power, lighting, heating and ventilation-should be based on a modular plan. Local supplies may sometimes be preferable to a permanent central installation. For example, direct current can conveniently be supplied from individual power packs instead of from a central battery. Similarly, vacuum requirements can usually be provided by bench pumps, and supplies of various gases from local cylinders. Facilities must be available, however, for the handling and storage of gas cylinders. An adequate and easily accessible duct system should always be installed to enable any central service to be provided at any point if it is found to be desirable in the future.

Mr. J. C. Cornwell discussed buildings and services from the point of view of the laboratory maintenance engineer. He pointed out that maintenance staffs in laboratories are more often concerned with alterations and additions to the buildings and facilities than with simply maintaining the original installation. When the laboratory is designed, provision should be made to facilitate building extensions and alterations to the services. In the choice of partitioning, sound transmission and ease of atterchment of shelves are important considerations. Brick and some proprietary types of partitioning are satisfactory, but steel and glass are not. Floor surfaces and their cleaning merit particular attention. Floor ducts should be designed to minimize flooding. Fire protection should receive adequate consideration. Provision must be made for inflammable stores, radioactive sources, gas cylinders and bulky maintenance equipment.

Mr. R. G. Hopkinson spoke on the programme of research on the design of laboratories which is being carried out by the Nuffield Foundation Division for Architectural Studies in collaboration with the Building Research Station. Statistical studies have been made of the bench space and services required by laboratory workers. The work on laboratory lighting was carried out at the Building Research Station. From the determinations of minimum levels of natural and artificial lighting for the efficient performance of laboratory work, a design has been evolved which gives good day-lighting in a single-side lit laboratory. A model was used for assisting in the appraisal of the design (Musgrove, J., and Petherbridge, P., Architect's J., 126, 368 ; 1957).

In opening the discussion, Mr. D. A. Oliver suggested that two types of laboratory accommodation are generally required-'open space', costing about f2 per sq. ft., and 'better-class' laboratory accommodation costing about $£ 410 \mathrm{~s}$. per sq. ft. The better-class accommodation should be kept free from noise, vibration and dirt; workshops and heavy machines should be in a separate building.

Other matters discussed were the advantages of air conditioning and electric floor warming in research laboratories; a method of providing a wide range of electricity supplies at the benches; and a colourlight staff location system which also functioned as a fire alarm.

In summing up the symposium, Prof. F. A. Vick said that the physicist must make up his own mind as to his requirements, but it is sometimes important that the outside of laboratory buildings should be in keeping with other adjacent buildings. The use of models could be a great help in planning laboratories. Workshops and equipment causing noise and vibration should be kept separate from the research laboratories and offices. The services should. be very carefully designed bearing in mind the many points raised in the discussion, and detailed plans of the services properly colour-coded should be handed over with the building. The laboratory furniture should be designed as part of the building. He agreed that it is false economy to save money on the initial cost of the laboratory-taken over a number of years the capital cost of buildings is not usually a very important item in the research laboratory budget.

J. S. Forrest

\section{COLOUR TELEVISION IN UNIVERSITY TEACHING}

\section{GUY'S HOSPITAL AND MEDICAL SCHOOL}

$J$ and the British Broadcesting Corporation collaborated to present a series of sixteen demonstrations, lasting more than two hours, which was relayed from Alexandra Palace to Western House, Great Portland Street, London, on the evening of November 19. Marconi's Wireless Telegraph Co., Ltd., provided a colour television projector and a $6 \mathrm{ft}$. $\times 4 \mathrm{ft}$. screen. Although this presentation had been organized for the staff of Guy's Hospitel and the Medical School, a large number of representatives from other faculties in the University of London and from medical centres elsewhere were also present.

The purpose was to judge the technical quality of the British system and to consider whether the apparent and potential properties of colour television are sufficiently attractive to warrant a critical trial under practical conditions.

This venture was by no means a stunt. Repeated technical experiments in the research establishment of the Marconi Company at Chelmsford preceded further trials at Alexandra Palace by members of the staff at Guy's representing fourteen different depart. ments. The B.B.C.'s production staff had to evolve new methods and to adapt their equipment to a considerable extent. For example, teaching demonstrations were found to require big close-ups, whereas existing techniques had naturally been designed to satisfy the demands of the theatrical producer. It may be of interest to note that this was the first occasion on which the B.B.C. has transmitted a continuous colour television programme of this length. Meticulous planning was necessary to enable the two cameras to move from one demonstration to the next in less than two minutes. That the presentations followed each other with quite extraordinary precision was the more remarkable as few of the busy physicians and lecturers had been able to attend more than one or two rehearsals. This is a point of importance, as it might be assumed that television techniques in medical teaching will exact undue demands upon the lecturer's time.

The general consensus of opinion was that the quality of definition and colour balance was well above reasonable expectation and most certainly made the use of colour television a practical possibility. It is still to be decided whether this method of communication should be further tested for its effectiveness by a series of critical experiments carried out egainst the background of university teaching. It was not pos. sible on this occasion to draw any valid conclusions in this respect. The audience consisted of experienced teachers and not students, most of the demonstra. tions were enacted by senior lecturers, who would normally have been directing such work while 
actually with their students ; and, of course, a large technical staff was available to handle intricate and bulky equipment. Both equipment and methods will have to be simplified drastically to adapt this medium for use in everyday instruction, and there is every expectation that this could be done. However, only practical experience under realistic conditions will show to what extent and how colour television can contribute to understanding and learning.

It may be of value to consider here the essential properties of colour television and how they might possibly be applied. Events and phenomena can be observed at a distance, even when direct vision is not possible. The moving image can be viewed either on large projection screens, or on smaller television receivers in any desired number of places, by large audiences, at the exact time that events are taking place. Fine detail, such as individual hairs on the back of the hand, and large scenes, such as big machinery in a laboratory, can be portrayed with equal ease. High-power microscopic examinations can be made with considerably higher brilliance than is possible with conventional projection microscopes. Preliminary experiments with endoscopes have proved that their use may well become a commonplace, as soon as the associated optical problems have been solved. Live presentation, films, slides and charts can be shown in immediate sequence, and indeed in any desired admixture.

The images from two or more television cameras can be presented in sequence or even side by side. It will thus be possible to correlate separate aspects of the same subject or to contrast similar phenomena by using more than one camera in quite different locations, as, for example, in a laboratory and in a hospital ward.

Perhaps the most important difference from normal visual records such as diagrams, lantern slides and motion picture films is the fact that a live action is shown on the television screen at the exact moment when it happens. Apart from any other considerations, the psychological effect of this upon a student body may prove to be considerable. Whereas a film is rigid in its construction and presentation and cannot easily be arrested, the television demonstration is entirely under the lecturer's control. He can direct the demonstrator through a two-way radio link, he can ask for an alternative presentation of the same subject or for a repetition when he feels that this would be of greater benefit to the students. Mistakes and defects can be rectified immediately, a process which may in fact add to the value of a demonstration, by emphasizing its immediate and local character, and thus imparting to it a liveliness and personal nature often absent from films. Each demonstration cen be varied according to the lecturer's wishes and according to the existing knowledge of his students. Participation by the audience can be used where appropriate, for students can both hear and speak to the demonstrator who is with the camera.

Many will maintain that the motion picture film can be used as effectively and more economically. A brief consideration of this contention will expose its fallacy. Even if funds could be raised to establish and maintain sufficient film production units to make films of all the many subjects which can be shown by television, fow teachers would have the time required for drafting the initial treatment and for supervising the scripting, rehearsing, shooting and editing of such films. Even if all these films could be made, they would neither fit in with the ideas of other teachers, nor could they possibly be equally effective for different types of audiences. Some 'date' quickly and there are inevitable delays between preparation and exhibition.

Such handicaps do not apply to television. The lecturer discusses with his assistant what he wishes to demonstrate. The camera is placed in position, and the lecturer can direct and control the proceodings as and when he requires them while talking to his students. This demonstration can be as simple or elaborate as he himself may wish.

The use of good colour, a live presentation, the magnification of small detail for large audiences, the juxtaposition of different events or phenomena separated in space, participation by the audience, and complete control by the lecturer can be regarded as the main characteristics which might be exploited. What effect, in terms of understanding and learning, might this have on students? Which type of student will derive the greatest benefit from colour television and at what stage of his learning? Which teaching situations and which disciplines are most likely to benefit from its use? How should it be used to its best advantage ? Finally, is the total effect economically worth while? The answers to these questions can only be established satisfactorily when a centre consisting of many different interests and types of student, both undergraduate and postgraduate, is prepared to underteke a full and unbiased investigation of the method. No one will be optimistic enough to imagine that colour television can solve all problems of teaching, nor will any responsible teacher wish to interpose an elaborate electronic device between himself and his class where the normal direct approach can do all he wishes. Nevertheless, experience already shows that television demonstration may permit valuable additions to the content of teaching in many medical subjects, especially by presentation to large audiences of things it is rarely possible to show even to a handful of students. Doubtless, present views and expectations will be modified, and unsuspected potentialities discovered, when it becomes possible to make a full exploration in the working conditions of a medical centre. The results of such an experiment might prove to have far-reaching effects on education, not only in university circles, but also in schools and perhaps even on television broadeasts to the general public.

A colour sound film recording of the demonstration and a booklet published by Marconi's Wireless Telegraph Co. in collaboration with the Illustration Department of Guy's Hospital Medical School are available.

C. E. ENGEL

ROGER WARWICK

\section{AUTOMATION IN THE POST OFFICE}

IN moving the second reading of the Post Office and Telegraph (Money) Bill in the House of Commons on December 5, the Postmaster-General, Mr. E. Marples, said that during the next two years the Post Office would be spending about $£ 180$ million on capital equipment, of which $£ 105$ million would be by way of depreciation and ploughed back by the Post Office. Of this sum, more than $£ 167$ million would go to telecommunications, $£ 6$ million to tolegraphs-mostly 'Telex' - and $£ 7$ million to postal 